\title{
Challenges in the Development of Novel Treatment Strategies for Neuropathic Pain
}

\author{
Michael H. Ossipov and Frank Porreca \\ Department of Pharmacology, College of Medicine, University of Arizona, Tucson, Arizona 85724
}

\begin{abstract}
Summary: Neuropathic pain might best be considered as a collection of various pain states with a common feature, that being symptoms suggestive of dysfunction of peripheral nerves. The development of therapeutic options for the treatment of neuropathic pain is complicated significantly by several factors. Neuropathic pain may arise from widely diverse etiologies such as physical trauma, disease, infection, or chemotherapy. Symptoms indicative of neuropathic pain may also arise in individuals with no evidence of any type of nerve trauma (idiopathic). Although neuropathic pain is a substantial health care issue, it is relatively uncommon and only occurs in a small fraction $(<10 \%)$ of individuals with these initiating factors. Moreover, the efficacy of treatment protocols, even against the same type of symptoms, differ depending on the underlying initiating cause of the neuropathy. Although these observations strongly suggest that there are predisposing factors that may impart susceptibility to the development of neuropathic pain, no common predisposing factors or genetic markers have been satisfactorily identified. Because of these
\end{abstract}

vagaries, treatment of neuropathic pain has been based on trial and error. However, recent progress in the understanding of neurophysiologic changes that accompany peripheral nerve dysfunction indicate that regulation of ion channels that maintain membrane potentials or generate action potentials may provide an important therapeutic approach. Neuropathic pain is accompanied by increased activity of peripheral nociceptors, which is produced in part by changes in levels of specific calcium and sodium channels. The identification of sodium and/or calcium channels subtypes that are expressed almost exclusively on nocicpetors may provide a way of regulating the activity of exaggerated nociceptor function without altering other sensory modalities. Thus, the selective targeting of ion channels may represent a viable therapeutic target for the management of the neuropathic pain state, regardless of etiology. Key Words: Neuropathic pain, diabetic peripheral neuropathy, post-herpetic neuralgia, complex regional pain syndrome, voltage-gated ion channels, allodynia, and hyperesthesia.

\section{NEUROPATHIC PAIN: DEFINITIONS AND CLINICAL CONSIDERATIONS}

Although neuropathic pain might accurately be considered a disease state, it is more generally thought of as a collection of chronic pain syndromes with a common feature, that being dysfunction of peripheral sensory nerves or nerves within the CNS. The definition of peripheral neuropathic pain, according to the International Association for the Study of Pain (IASP) is "Pain initiated or caused by a primary lesion or dysfunction in the peripheral nervous system."1 Neuropathic pain of peripheral origin is not merely a condition arising from a single event that diminishes as healing from the original insult progresses, but rather is an abnormal pain state that it is maintained long after the initiating event has resolved. ${ }^{1}$

Address correspondence and reprint requests to Frank Porreca, Ph.D., Department of Pharmacology, University of Arizona HSC, Tucson, AZ 85724. E-mail: frankp@u.arizona.edu.
Of the neuropathic pain conditions, those associated with nerve trauma have received the lion's share of clinical investigation and consequently are the best described. ${ }^{2}$ In fact, abnormal chronic pain states along with changes suggestive of trophic and autonomic alterations were described during the American Civil War. Weir Mitchell described trophic signs, glossy skin, and burning pain that developed in large numbers of soldiers with bullet wounds as causalgia. ${ }^{3-5}$ Some soldiers with bullet wounds and nerve damage developed a syndrome of burning pain, hyperesthesia, glossy skin, rubor, edema, and skin that would appear colder than the uninjured parts of the body. This term causalgia arose from the Greek term for burning pain. Causalgia was initially thought of as a unique class of neuropathic pain caused by nerve trauma delivered by a high-velocity missile impact. Such pain was characterized by persistent burning sensations of the hands and/or feet after a highvelocity missile impact (i.e., bullet wound) involving 
TABLE 1. Symptom of Neuropathy

Various Symptoms of Neuropathic Pain

\begin{tabular}{|c|c|c|c|}
\hline Spontaneous Symptoms & $\begin{array}{l}\text { Spontaneous burning sensation } \\
\text { Deep ache in limbs } \\
\text { Stinging or prickly sensations } \\
\text { Shock-like lancinating } \\
\text { Paroxysmal shooting electrical pain }\end{array}$ & Evoked Symptoms & $\begin{array}{l}\text { Allodynia to touch } \\
\text { Allodynia to cold } \\
\text { Hyperalgesia } \\
\text { Hyperpathia (evoked pain is } \\
\text { maintained after the stim- } \\
\text { ulus is terminated) }\end{array}$ \\
\hline Hyperesthesia & Nonpainful Symptoms & \multicolumn{2}{|c|}{$\begin{array}{l}\text { Increased sensitivity to sensory stimuli. Includes } \\
\text { nonpainful stimuli, but can include allodynia and } \\
\text { hyperalgesia }\end{array}$} \\
\hline Paresthesia & & \multicolumn{2}{|c|}{ Not unpleasant abnormal sensation } \\
\hline Dysesthesia & & \multirow{2}{*}{\multicolumn{2}{|c|}{$\begin{array}{l}\text { Unpleasant, but not painful, abnormal sensation } \\
\text { Increased threshold and/or decreased sensitivity to } \\
\text { sensory stimuli }\end{array}$}} \\
\hline Hpoesthesia/hypoalgesia & & & \\
\hline
\end{tabular}

Descriptions are based on IASP nomenclature ${ }^{1}$ and recent reviews. ${ }^{7,16,22,34}$

peripheral nerves of the arms or legs, and might be accompanied by red, glossy, and edematous skin. ${ }^{6}$ Causalgia was considered to be a subset of reflex sympathetic dystrophy, or sympathetically maintained pain. This neuropathic pain syndrome is indicated by spontaneous burning sensation and/or the presence of allodynia or hyperpathia to light touch. ${ }^{6}$ It has been reported that sympathetic blockade, including complete surgical sympathectomy, permanent chemical sympathectomy with phenol, or systemic sympatholytics abolish both the adverse pain condition and the trophic changes, especially when performed soon after the insult. ${ }^{6,7}$ Although previously expressed as an independent form of neuropathic pain, it is now recognized that sympathetically maintained pain may be a component of neuropathic pain in some, but not all, patients, regardless of the initiating factor. A sympathetic component has been described in neuralgias including postherptic neuralgia $(\mathrm{PHN})$, metabolic neuropathies, and phantom limb pain. ${ }^{8}$ Based on our growing understanding of the symptomology of these chronic pain states, conditions earlier classified as causalgia, reflex sympathetic dystrophy, and sympathetically maintained pain have been grouped as complex regional pain syndrome (CRPS), which is indicated clinically by hyperalgesia and allodynia, pain disproportionate to the injury, dyesthesias and hyperesthesias, or hyperalgesia that extends beyond the territory of the injury, along with autonomic, trophic and motor changes. ${ }^{8-10}$ CRPS includes sympathetically maintained or sympathetic-independent pain, with undefined underlying mechanisms and many treatment options with unpredictable outcomes. ${ }^{9,10}$ It is now suggested that perhaps 3-5\% of CRPS is sympathetically maintained. ${ }^{11,12}$ Furthermore, CRPS is subdivided into CRPS-I and CPRS-II. ${ }^{8}$ CPRS-II is defined by spontaneous pain and hyperalgesia or allodynia, along with the presence, or evidence of previously present, edema, abnormal blood flow, and autonomic, trophic, or sudomotor abnormalities, and is distinguished from type I by the clear indication of nerve trauma. ${ }^{1,7,8,13}$ The signs and symptoms of CPRS-I are the same as those of CPRS-II, except that there is no verifiable damage to a peripheral nerve..$^{1,7,9,10}$ By definition, it is precipitated by a noxious event that might include fractures, joint sprains, strains, thoracic surgery, soft tissue injury, and cardiac ischemia. ${ }^{5-7,14}$ Idiopathic CRPS-I has been described as sequella to noxious events so trivial patients may not remember the occurrence, and include venipuncture, lacerations, and other types of minor trauma. ${ }^{6,7}$ Because of the absence of verified injury, the inclusion of CPRS-I as a neuropathic pain state has been challenged. ${ }^{15}$ However, it has been strongly argued that the symptomology is consistent with neuropathic pain, and that the signs and symptoms, and not the etiology of the condition, should drive the therapeutic options. ${ }^{16-18}$

Diabetic peripheral neuropathy (DPN) and PHN are two important clinical neuropathic pain syndromes that have been extensively studied with regard to establishing treatment regimens for neuropathic pain. ${ }^{19}$ Like the traumatic pain syndromes described above, DPN and PHN are associated with spontaneous, episodic pain and evoked pain, including allodynia in response to touch, cold, or heated tactile stimuli, and light brush (dynamic allodynia). ${ }^{19}$ DPN has been defined as including "symptoms and/or signs of peripheral nerve dysfunction in people with diabetes after the exclusion of other causes." 20,21 The causes of DPN are not clearly understood but are believed to include release of toxic metabolites, alterations in growth factors, a compromised microvasculature, and possible inflammatory events. ${ }^{22}$ Pathological changes are observed in $\mathrm{A} \beta, \mathrm{A} \delta$, and $\mathrm{C}$-fibers, which help explain the fact that diabetic patients present with varying signs and symptoms that range from complete nonpainful anesthesia of the feet to severe neuropathic 
TABLE 2. Etiologies and Neuronal Dysfunctions Associated with Neuropathic Pain

\begin{tabular}{lll}
\hline Physical & & Organic \\
\hline Nerve section, axotomy & Postherpetic neuralgia & Vincristine \\
Nerve compression & Trigeminal neuralgia & Paclitaxel \\
Nerve traction & Diabetic & Cisplatin \\
Thoracotomy & Alcoholic & Heavy metals \\
& Idiopathic (e.g., burning feet syndrome) & \\
& Malignancies & \\
& Infections (HIV, hepatitis, leprosy, lyme disease) & \\
\hline
\end{tabular}

This table is based on recent reviews of neuropathic pain. , $^{2,6,13}$

pain (see Table 1). ${ }^{20}$ Although DPN usually involves the extremities, it may also involve thoracic or cranial regions where it presents either symmetrically or asymmetrically, and may occur from ischemia or nerve entrapment in addition to the progression of the disease. ${ }^{22}$ PHN is a very painful neuropathic condition that is still present between 1 and 6 months after the herpes zoster (shingles) has cleared, representing a transition from acute herpes zoster to PHN. ${ }^{23-25}$ It has been described as an intermittent pain or can present as a persistent, but fluctuating, pain. ${ }^{24,25}$ Patients with PHN describe it as burning, itching, throbbing or a shooting pain, and dyesthesias may be present. ${ }^{24,25}$ Like DPN, PHN has been associated with neuroinflammation and a loss of large and small sensory fibers. ${ }^{26}$ The etiology of neuropathic pain states encompasses many other conditions, including prolonged treatment with chemotherapeutic agents, infections such as HIV, and from idiopathic and genetic sources. The common causes of neuropathic pain are listed in Table 2.

It has been suggested that changes in innervation of the hypersensitized skin area along with changes in spinal processing may contribute to neuropathic pain in PHN. ${ }^{27,28}$ The examination of skin biopsies taken from regions affected by PHN demonstrated that the severity of allodynia was inversely correlated with the loss of sensory nerve endings in the skin. ${ }^{27}$ Punch skin biopsies were taken from patients with shingles and with or without PHN and immunostained with the axonal marker anti-PGP9.5. ${ }^{29}$ Those with neuropathic pain showed an epidermal neurite density of only $339 \pm 97$ epidermal neurites $/ \mathrm{mm}^{2}$ of skin surface area compared with a density of $1661 \pm 262$ neurites $/ \mathrm{mm}^{2}$ of skin surface area from the pain-free patients. ${ }^{29}$ Because nearly all epidermal neurites are sensitive to capsaicin, these observations indicate a loss of nociception innervation. ${ }^{29}$ It is suggested that allodynia and hyperalgesia after PHN may be due to hypersensitivity of the remaining nociceptors along with abnormal spinal processing of the afferent inputs. ${ }^{28-30}$ In a recent study, the neurite density of skin punches taken from the most painful region from patients with PHN and from analogous regions in pain-free patients with shingles was evaluated and it was determined that minimum of approximately 650 neurites $/ \mathrm{mm}^{2}$ was needed to prevent the development of PHN. ${ }^{28}$ Because the degeneration of the peripheral branch of a primary afferent fiber leads ultimately to the degeneration of its central projection as well, it is suggested that the loss of these primary afferents cause a compensatory hyperactivity of the second-order projection neurons. ${ }^{28}$ Accordingly, dorsal horn atrophy was reported in patients with PHN after shingles. ${ }^{31,32}$ Furthermore, MRI studies performed on the spinal cord of patients after a herpes zoster outbreak showed abnormal deafferentation only in those that developed PHN. ${ }^{26}$

Neuropathic pain is best considered as a complex set of abnormal physiologic processes incited by trauma, a noxious event or a disease state. ${ }^{22,33}$ Accordingly, it should not be considered as a syndrome in and of itself, but as a symptom of other neurologic dysfunctions. It presents in various ways in different patients, and the presentation and susceptibility to treatment of neuropathic pain is widely recognized by clinicians as being quite unpredictable. ${ }^{33,34}$ Taken together, these factors suggest that an organic basis, possibly driven by genetic factors, may underlie a patient's susceptibility to the development of neuropathic pain. The challenge before us is to determine the mechanisms that drive neuropathic pain in humans. Moreover, it is imperative to learn why only a small group of people develop neuropathic pain after events that leave a much larger population unaffected. More adequately controlled clinical studies are needed to move us beyond the era of "trial and error" and into physiologically based rational therapeutic protocols. For all of these reasons, "effective new strategies are desperately needed."

\section{CURRENT STATE OF THE ART: PROPOSED MECHANISMS OF NEUROPATHIC PAIN}

\section{Increased Neuronal Excitation}

Considerable progress has been made over the past three decades with regard to our understanding of the mechanisms that may mediate neuropathic pain. Animal models of peripheral nerve injury have led to the description of several mechanisms that may drive neuropathic 
pain. These mechanisms include neuroplastic adaptations in the peripheral nerves, dorsal root ganglia, and the spinal cord including upregulation and/or downregulation of neuropeptides and neurotransmitters, and/or alterations in the phenotypic expression of peripheral nerves where neuropeptides not normally present are abundantly expressed, whereas normally expressed neuropeptides are suppressed. These changes in expression of neurochemical markers correlate with the development of tactile and thermal hypersensitivity in animals and with an increase in evoked release of excitatory neuropeptides from primary afferent terminals. Moreover, there is growing evidence that peripheral nerve injury elicits neuroplastic changes at supraspinal sites that mediate a spinopetal pain facilitatory system. This descending pain facilitatory system acts to maintain a sensitized state of the spinal cord, demonstrated by increased responsiveness of second order neurons of the spinal dorsal horn to sensory inputs, increased receptive field size, and recruitment of adjacent nerves, along with increased transmitter release from primary afferents promoting afferent inputs and enhancing the transmission of pain signals to higher brain centers. Despite the fact that there are numerous studies in animal models that led to these generalized observations, it is often difficult to translate the observations made in these types of studies into practical clinical terms. Correspondingly, it is also difficult to reliably predict novel therapeutic interventions based on such observations. These mechanisms of neuropathic pain are reviewed in detail elsewhere. ${ }^{35-39}$

One of the hallmarks of peripheral nerve dysfunction is seen in the alterations in conductance properties of the peripheral nerves and increased spontaneous and evoked ectopic discharges. The increased neuronal activity is believed to lead to sensitization of the spinal cord and to drive neuropathic pain. Circumstantial evidence that neuronal excitation may mediate neuropathic pain is found by the fact that agents such as local anesthetics, antiepileptics, and tricyclic antidepressants has abolished neuropathic pain in some instances. ${ }^{40-42}$ Systemic or topical lidocaine has provided some relief in patients with PHN. ${ }^{43,44}$ Most recently, mutations of a gene coding for a subunit of the $\mathrm{Na}_{\mathrm{V}} 1.7$ VGSC was found responsible for the development of autosomal erythermalgia. ${ }^{45}$ The possibility that sensitization to pain may arise from a neuroma after axotomy was suggested when dyesthesias and pain elicited by palpation or mechanical distortion of the neuroma was abolished by lidocaine. ${ }^{46}$ Recordings were performed in patients with different types of peripheral nerve dysfunctions by impaling a tungsten microelectrode into the fascicle of a skin nerve. ${ }^{47}$ Recordings performed from the sural nerve of a 47-year-old male with sciatic pain showed that the changes in multiunit activity correlated with the increases and decreases in intensity of dyesthesias. ${ }^{47}$ In the same study, a patient with radicular pain of the lower leg showed spontaneous neuronal activity and distinct discharges in response to light stroking of the receptive field. ${ }^{47}$ Phantom limb pain was accompanied by spontaneous peripheral nerve activity. ${ }^{48}$ Tapping the neuromata caused enhanced pain along with enhanced neuronal discharges. ${ }^{48}$ The evoked discharges and pain were blocked by lidocaine, whereas the spontaneous activity was not. ${ }^{48}$ The correlation between ectopic discharges and neuropathic pain has been repeatedly demonstrated in man. ${ }^{49,50}$

In animal studies, it was demonstrated that neuroma formation after axotomy results in spontaneous ectopic discharges from the site of injury. ${ }^{51-54}$ Spontaneous ectopic discharges are generated from the area of injury and also from the DRG of injured peripheral nerves. ${ }^{55-57}$ Electrophysiological recordings from injured sciatic nerves demonstrated spontaneous ectopic discharges from the region of injury and hyperexcitability to light touch. ${ }^{58,59}$ Sensitization appears to be mediated in part by enhanced activity and concentrations of sodium channels. Ultrastructural analyses of neuromas suggested extensive remodeling of sodium channels at the endbulbs that are responsible for the abnormal electrical activity associated with ectopic discharges. ${ }^{60}$ The endbulbs of both small-diameter and demyelinated large-diameter fibers within the neuroma show an accumulation of sodium channels, which may mediate the hyperexcitability of injured nerves. ${ }^{61,62}$

Because of their critical role in the generation of action potentials and neuronal excitation, the increased abnormal spontaneous and ectopic discharges of injured peripheral nerves are related to increased activity of voltage-gated sodium channels (VGSCs). ${ }^{51-54,63}$ The VGSCs have been linked to excitability of primary afferent nociceptors and may mediate sensitized pain states. ${ }^{41,63}$ Peripheral nerve injury is also associated with changes in the expression and distribution of isoforms of the VGSCs. ${ }^{40}$

The VGSCs have been characterized on the basis of their biophysical characteristics and resistance to tetrodotoxin. ${ }^{40,41,64}$ The VGSCs that are sensitive to TTX (TTX-S) have a low threshold for activation (between -55 and $-40 \mathrm{mV}$ ), are rapidly activating, and are rapidly inactivating. Approximately $50 \%$ of these channels are available for activation at potentials close to resting membrane potential. ${ }^{65}$ The TTX resistant (TTX-R) VGSCs have been further subdivided based on electrophysiologic characteristics. One of these TTX-R currents is similar in function to the TTX-S channels and is labeled the TTX- R3. ${ }^{66}$ or fast TTX-R current. ${ }^{67}$ A second TTX-R (TTX-R1) current is resistant to TTX, has a high activation threshold, and activates and inactivates relatively slowly, but reprimes rapidly, and may act as a pacemaker channel. ${ }^{65}$ This current may account for the high activation threshold observed in nociceptive affer- 
ents. ${ }^{68}$ The TTX-R channels can initiate action potentials in polymodal nociceptive afferents, and because these sites are close to the axon terminals, they also contribute to transmitter release from nociceptive afferents. ${ }^{63,69}$ The VGSCs are clearly linked to neuronal excitability, and changes in populations of these channels may enhance the ability of sensory neurons to respond to external stimuli, and may mediate sensitized pain states.

The nine identified isoforms of the VGSCs are differentially distributed throughout the body. Importantly, however, their distribution is altered after peripheral nerve injury, and the novel expression of a VGSC isoform may contribute to neuronal excitation and neuropathic pain. ${ }^{40,41}$ The involvement of some of these subtypes of sodium channels in neuropathic pain states are summarized briefly below.

\section{$\mathrm{Na}_{\mathbf{v}} 1.3$}

The TTX-S channel $\mathrm{Na}_{\mathrm{V}} 1.3$ is fast activating and is found in the brain and at very low levels in the DRG. After peripheral nerve injury, there is a substantial expression of $\mathrm{Na}_{\mathrm{V}} 1.3$ in DRG neurons, and it is believed that this novel expression may be partly responsible for the enhanced excitability and of primary afferents after nerve injury because its biophysical properties favor generation of spontaneous discharges. ${ }^{40,41,65}$ However, a causal relationship between expression of $\mathrm{Na}_{\mathrm{V}} 1.3$ in the DRG and neuronal discharges has not been established. Recently, it was found that upregulation of $\mathrm{Na}_{\mathrm{V}} 1.3$ in second-order neurons of the dorsal horn of the spinal cord caused by nerve injury enhanced the responsiveness of these neurons to noxious stimuli. ${ }^{70}$ Knock-down of $\mathrm{Na}_{\mathrm{V}} 1.3$ by antisense treatment abolished both the enhanced neuronal activity and behavioral signs of neuropathic pain in nerve-injured rats. ${ }^{70}$

\section{$\mathrm{Na}_{\mathbf{v}} 1.7$}

The TTX-S VGSC $\mathrm{Na}_{\mathrm{V}} 1.7$ is found predominantly in small-diameter sensory DRG neurons and in sympathetic nerves. ${ }^{71}$ It is upregulated after carrageenan-induced inflammation, suggesting a pronociceptive role. ${ }^{71}$ The generation of genetically modified mice with knock-down of the $\mathrm{Na}_{\mathrm{V}} 1.7$ channel of sensory neurons while sparing sympathetic nerves resulted in mice with reduced sensitivity to noxious mechanical, but not thermal, nociception and reduced inflammation-induced hyperalgesia. ${ }^{72}$ Transfection of HEK293 cells with two different mutations of human DNA for $\mathrm{Na}_{\mathrm{v}} 1.7$ that are associated with familial autosomal erythermalgia showed that the mutated channel produced a hyperpolarizing shift in activation, slowed deactivation of the channel and markedly increased the ramp current, with the net effect being a marked hyperexcitation of the cells. ${ }^{73}$ These alterations would be consistent with enhanced nociception and sympathetic activity and could account for the etiology of erythermalgia. ${ }^{73}$ More recently, voltage clamp studies performed on transfected mouse DRG cells showed that the human mutations lowered the thresholds for generation of action potentials and repetitive firing, thus provoking high-frequency firing of nociceptive small diameter sensory neurons in the DRG. ${ }^{74}$

\section{$\mathrm{Na}_{\mathrm{v}} 1.8$}

The role of the TTX- $\mathrm{R}$ channel $\mathrm{Na}_{\mathrm{V}} 1.8$ has been studied more extensively. It is found exclusively in smalldiameter nociceptors and is critical to the generation of action potentials and nociceptors function. ${ }^{40,41,71}$ After axotomy or tight ligation, there was an accumulation of $\mathrm{Na}_{\mathrm{v}} 1.8$ proximal to the injury, suggesting that this clustering may participate in the generation of ectopic discharges. ${ }^{40,41,75}$ Moreover, nerve injury caused a downregulation of $\mathrm{Na}_{\mathrm{V}} 1.8$ protein and current in the DRG of injured neurons but upregulation predominantly in Cfiber nociceptors in adjacent, uninjured DRG neurons, along with an increase in TTX-R compound action potential at $\mathrm{C}$-fiber conduction velocity. ${ }^{75-77}$ Antisense knock-down of the redistribution of $\mathrm{Na}_{\mathrm{V}} 1.8$ after spinal nerve ligation prevented the upregulation of $\mathrm{Na}_{\mathrm{v}} 1.8$ in adjacent neurons and abolished tactile and thermal hypersensitivities without altering normal baseline sensory responses. ${ }^{75}$ Finally, $\mathrm{Na}_{\mathrm{V}} 1.8$ immunoreactivity is evident in peripheral nerve tissues from patients with chronic neuropathic pain. ${ }^{78,79}$

\section{$\mathrm{Na}_{\mathbf{v}} 1.9$}

Like $\mathrm{Na}_{\mathrm{V}} 1.8, \mathrm{Na}_{\mathrm{V}} 1.9$ is a TTX- $\mathrm{R}$ channel that is expressed exclusively in peripheral nociceptors. ${ }^{80}$ It maintains a persistent sodium current close to the membrane resting potential, ${ }^{71}$ inactivates slowly and incompletely, and does not generate action potentials but sets the membrane potentials and activating thresholds. ${ }^{71}$ Knockdown of this channel by antisense did not abolish either thermal hyperalgesia or tactile hypersensitivity in rats with nerve injury. ${ }^{77}$ The role of this channel in the neuropathic pain state is unclear. This channel appears to underlie enhanced nociceptive responses after inflammation, and its activity may be enhanced by inflammatory mediators. ${ }^{81}$

\section{Calcium Channels}

The calcium channels have been classified as L, N, P, $\mathrm{Q}, \mathrm{R}$, and $\mathrm{T}$ type, based on pharmacologic and electrophysiologic characteristics. ${ }^{82}$ The N-type calcium channel was identified in DRG neurons and characterized by an intermediate level of voltage-dependence and rate of inactivation. ${ }^{83}$ It is blocked by $\omega$-conotoxin. ${ }^{84}$ This channel is predominant in the superficial lamina of the spinal dorsal horn and is likely to participate in nociceptive transmission. ${ }^{85}$ The N-type calcium channel appears to be essential for depolarization-coupled release of neurotransmitters, including substance P, CGRP, and glutamate, from primary afferents and neuronal excitability. ${ }^{86}$ 
The ability of the $\omega$-conotoxin-GVIA to block electrically evoked responses of dorsal horn neurons was enhanced in nerve-injured rats. ${ }^{87}$ In addition, blockade of the N-type calcium channel with $\omega$-conotoxin-GVIA also abolished injury-induced wind-up and post-discharge phenomena. ${ }^{87}$ It was suggested that nerve injury results in either increased frequency of opening of the $\mathrm{N}$-type calcium channel, or an increase in the population. ${ }^{87}$ Blockade of these channels is expected to decrease the enhanced excitatory neurotransmitter release that occurs after nerve injury, thus inhibiting the manifestations of enhanced pain. ${ }^{87}$ The spinal administration of a novel N-type calcium channel blocker ziconitide, which is a synthetic analog of $\omega$-conotoxin MVIIA, produced antinociception in noninjured rats and abolished tactile and thermal hyperesthesias in rats with peripheral nerve injuries. ${ }^{88,89}$ Recent clinical trials with ziconotide (PRIALT) provide strong evidence that blockade of the $\mathrm{N}$-type calcium channel may provide a significant clinical means in the management of severe, refractory pain. ${ }^{90}$ Spinal administration of ziconotide diminished the morphine requirement for postsurgical pain relief. ${ }^{91}$ Ziconotide provided complete pain relief in a patient with intractable severe deafferentation pain. ${ }^{92}$ In a multicenter series of placebo-controlled, double-blind randomized clinical trials, spinal ziconotide produced moderate to complete pain relief in chronic pain patients with cancer or acquired immune deficiency syndrome (AIDS).$^{93}$ Phase II and phase III clinical trials have also demonstrated that ziconotide is effective in patients with phantom-limb pain, PHN, and HIV-related neuropathic pain, and that are refractory to opioids. ${ }^{94}$ Taken together, these studies show great promise for the use of blockers of the N-type calcium channels as a means of treating severe, refractory neuropathic pain.

The T-type calcium channel is present in the DRG and on second-order neurons of the dorsal horn of the spinal cord. Activation of the NK1 receptor and of the T-type voltage-gated calcium channel (VGCCs) acts synergistically with activation of the NMDA/calcium channel complex to facilitate firing of the NK1-expressing cells of lamina I, thus promoting central sensitization. ${ }^{95}$ This observation is consistent with the finding that T-type VGCC blockade abolished behavioral signs of neuropathic pain in rats with peripheral nerve injury. ${ }^{96}$ Ethosuximide or mibefradil given either systemically or locally into the hindpaw to rats with peripheral nerve injury produced a dose-dependent reversal of tactile and thermal hyperesthesias. ${ }^{96}$ Similarly, ethosuximide diminished electrophysiologic signs of wind-up and after-discharges in rats with nerve injury. ${ }^{97}$ These results are consistent with the T-type calcium channel mediating postsynaptic sensitization after injury. ${ }^{97}$ More recently, antisense knock-down of the T-type calcium channel in the DRG abolished nociceptive responses to acute nox- ious mechanical or thermal stimuli as well as enhanced tactile and thermal responses in nerve-injured animals. ${ }^{98}$

\section{CURRENT STATE OF THE ART: PHARMACOLOGIC TREATMENTS}

The treatment options available for the management of neuropathic pain are almost as diverse as the etiologies. ${ }^{19,99}$ Because of the diversity of the underlying initiating events, patient populations and manifestations of the different types of pain, there is no way to predict the possible outcome of a particular therapy. Although there are many pharmacologic and nonpharmacologic therapies available, it has been estimated that sufficient pain relief is obtained in only about one-half of neuropathic pain patients. ${ }^{2}$ Because there is no way of predicting the response of an individual to a particular therapeutic intervention, there is no single, "best" or ideal treatment option. ${ }^{19,22,100}$ Therapeutic strategies have been described as being based on "trial and error." 2

The use of opioids as an effective means of treating neuropathic pain has been controversial in the past. ${ }^{101-103}$ Part of the reason for this controversy was the relative dearth of controlled clinical trials. ${ }^{104,105}$ Several recent studies have suggested that opioid therapies are active against certain forms of neuropathic pain. ${ }^{22,106}$ For example, randomized clinical studies showed that orally active opioids such as oxycodone have produced satisfactory pain relief in patients with $\mathrm{PHN}^{107,108}$ and DPN. ${ }^{109}$ Controlled release oxycodone reduced, but did not eliminate, paroxysmal spontaneous pain and allodynia in patients with PHN. ${ }^{108}$ In that study, 12 of 50 patients did not complete the trial, 6 of whom were receiving oxycodone, citing adverse effects. ${ }^{108}$ A recent randomized, double-blind clinical trial with patients presenting neuropathic pain from several conditions, including peripheral nerve damage and PHN showed that orally administered levorphanol reduced pain by $36 \%$ (high dose) and 21\% (low dose), but that secondary outcomes were similar between the two groups. ${ }^{105}$ Importantly, of the 81 neuropathic pain patients that began the trial, 22 did not complete the trial, citing adverse effects or inadequate pain relief. ${ }^{105}$ Similar observations were made in a double-blind, placebo-controlled, crossover trial examining the effects of opioids (morphine or methadone) and tricyclic antidepressants (nortriptyline or desipramine) in patients with PHN. ${ }^{107}$ Although the opioids were moderately superior to the TCA against pain, 20 of the initial 76 subjects dropped out during the opioid phase, whereas 6 subjects withdrew during the TCA phase. ${ }^{107}$ In these studies, adverse effects included changes in mood, irritability, personality changes, and decreased cognitive functions. ${ }^{105,107}$ It is telling that some individuals would abandon opioid therapy in spite of reduction in pain. In this regard, it is emphasized that neuropathic pain is a 
chronic condition and appropriate treatments need to be considered in the context of long-term therapy. Clearly, other therapeutic protocols must be considered.

Candidates for therapy against neuropathic pain include many more pharmacologic classes than only opioids. Varying degrees of success have been achieved with ion channel blockers, local anesthetics, gabapentin, anticonvulsants, and antiarrhythmics. However, the efficacy of these different classes against neuropathic pain is unpredictable and does not always correlate with findings from animal models. For example, mexilitine and dextromethorphan, considered an NMDA antagonist, both demonstrate activity in animal models of neuropathic pain yet have very limited effects in clinical cases at doses that can be tolerated by patients. ${ }^{16,22,110}$ Likewise, gabapentin is remarkably effective in animal models, yet effective only in certain subgroups of patients with CRPS or with PHN or DPN. ${ }^{16,110,111}$ Although intravenous lidocaine has been found effective against neuropathic pain due to nerve trauma, diabetes or PHN, topical administration of lidocaine is only effective against PHN, and may have limited efficacy in DPN. ${ }^{43,104,112}$ In contrast to lidocaine, mexilitine is remarkably ineffective in most neuropathic pain conditions, although it may block burning pain in patients with DPN. ${ }^{7,22,113}$ Capsaicin has been proposed as a treatment, but it must be applied at high concentrations, thus requiring anesthesia. ${ }^{22,114}$ Results with capsaicin are inconclusive. $^{22}$ Critical examinations of clinical trials for neuropathic pain reveal that, although there have been many studies performed, many of the studies suffer from design flaws, lack of proper controls, and many are not randomized, double-blind studies that are now prevalent in clinical research. ${ }^{104,115,116}$ Because of these deficiencies, many clinical studies have provided conflicting results regarding treatment options for neuropathic pain, making the selection of a proper therapeutic regimen particularly difficult. ${ }^{7,104,115,116}$ The critical consideration in determination of the therapeutic regimen is not necessarily efficacy, but the separation between the efficacy of a given pharmacologic agent and tolerability of side effects at doses effective in producing pain relief in the patient.

\section{CHALLENGES IN TREATMENT STRATEGIES FOR NEUROPATHIC PAINS: DIVERSE AND UNPREDICTABLE ETIOLOGY}

Although neuropathic pain is a severe, chronic pain state that adversely affects the quality of life of many individuals, most people that have a neuronal injury or dysfunction do not develop neuropathic pain. This implies very strongly that there are conditions that may predispose an individual to neuropathic pain. The more common sensory dysfunctions that are reported are non- painful conditions that include anesthesia in the area innervated by the injured nerve, hypoesthesia, parasthesias, or dyesthesias, which are unpleasant, but not painful. Neuropathic pain occurs in only about $5 \%$ of people that suffer from a nerve trauma. ${ }^{117}$ Population-based studies suggested that CRPS-I or CRPS-II develops in only $1-5 \%$ of individuals with a inciting event, such as bone fracture (for CRPS-I) or peripheral nerve injury (for CRPS-II) ${ }^{7,118}$ In two clinical studies that examined over 2,000 patients with amputations, only approximately $2 \%$ reported phantom limb pain, and its development appeared related to preamputation pain. ${ }^{119,120}$ Other patients with amputations reported phantom limb sensation but without pain. ${ }^{119}$ Causalgia reportedly occurs in only $2 \%$ of patients with bullet wounds involving peripheral nerves. ${ }^{6}$ Only $3-5 \%$ of patients receiving endodontic treatment develop orofacial neuropathic pain. ${ }^{121}$ One report states that PHN occurs in $20 \%$ of patients with an outbreak of herpes zoster. ${ }^{122}$ Other studies have placed the incidence of PHN after a herpes zoster outbreak at $8 \%,{ }^{123} 4 \%,{ }^{124}$ and $1 \%{ }^{125} 1$ year after healing of the rash. It has been estimated that $10-30 \%$ of diabetics suffer from neuropathic pain, whereas up to $50 \%$ of diabetics with neuronal dysfunction may be asymptomatic. $^{20,126,127}$ In a more recent study limited to type II diabetes in a population of 95 middle-aged, newly diagnosed patients, only $6.3 \%$ reported neuropathic symptoms. $^{128}$

Age may also be an important factor that influences the development of neuropathic pain. Generally, the risk of developing PHN increases with age. The development of PHN is uncommon generally, and quite rare in patients under 50 years of age. ${ }^{16,23}$ In a study of 821 cases of herpes zoster, only $8 \%$ of the subjects had PHN 30 days after the outbreak, and of these patients, $94 \%$ were over 50 years of age. ${ }^{124}$ Likewise, of the $4.5 \%$ of patients that had PHN 60 days after the onset of zoster, $96 \%$ of these were over $50 .{ }^{124}$ In other studies, it was found that there is a $27 \%$ likelihood that an episode of shingles will lead to PHN, whereas over the age of 60 , there is a $47 \%$ likelihood of postherpetic neuralgia after zoster eruption. Furthermore, over the age of 70 , there is a $48 \%$ likelihood that an episode of shingles will lead to pain persisting for more than 1 year. There was a significant elevation in thresholds to tactile, warm, and cold stimuli, but not to noxious thermal stimuli, in patients with PHN. ${ }^{129}$ In a study of 1,183 patients with nerve injury, it was found that the incidence of the initial onset of RSD (now called CRPS) was not correlated with age. ${ }^{130}$ The median age of patients with single RSD was 41 and that of patients with multiple RSD was 35, although the median age of patients with recurrence of RSD was said to be lower. ${ }^{130}$ In another study of 829 patients, it was found that there was no significant difference among age groups, with the exception that children under 10 years 
of age are less likely to develop CRPS. ${ }^{131}$ Allen and colleagues found that the incidence of patients with CPRS was distributed over the ages of 18-71 years with a mean of 41.8 years ${ }^{132}$ The importance of the results of these population studies should be considered in the development of therapeutic strategies for the treatment of neuropathic pain. Of all the individuals that have clinical syndromes that are known to incite pain development, only a relatively small percentage of these people actually do so. The critical question is to determine what it is that sets this small population apart from the vast majority of the rest of the population.

Sex differences in the development of some types of neuropathic pain have also been reported. An examination of patients with PHN found that women were more sensitive than men to noxious heat. ${ }^{129}$ Although it was reported that there was no statistical difference between men and women with regard to development of neuropathic pain after trauma, ${ }^{130}$ referrals to pain clinics show a different story. The examination of medical records of 134 patients referred for treatment for CRPS showed a female to male ratio of 2.3-1. ${ }^{132}$ Similar studies reported female to male ratios of $4.5-1,{ }^{133} 3-1 .^{131}$, and 1.6-1. ${ }^{134}$

\section{CHALLENGES IN TREATMENT STRATEGIES FOR NEUROPATHIC PAINS: GENETIC CONSIDERATIONS}

The wide variability in initiating factors, presentation and treatment outcome among individuals suggest the possibility of a genetic component that might predispose an individual to neuropathic pain. A genetic link was suggested when several studies have shown that blood levels of class I and class II major histocompatibility antigens(MHC) HLA-DR13, HLA-DR2, and HLADQ1are increased in women with CRPS. ${ }^{135,136}$ Moreover, CRPS patients with elevated HLA-DR13 levels tended to progress to a generalized dystonia, suggesting that this represented a distinct phenotype susceptible to neuropathic pain. ${ }^{137,138}$ Recently, it was found that the alleles D6S1014*134 and D6S1014*137, which are associated with expression of HLA-DR1, were significantly elevated in patients that developed CRPS after nerve trauma when compared with controls with trauma but without CRPS. ${ }^{139}$ It was speculated, based on the close association with the gene mapping for $\mathrm{GABA}_{\mathrm{B}}$, that there may be a link among this phenotype, $\mathrm{GABA}_{\mathrm{B}}$ receptor expression and CRPS, although this has not been established. ${ }^{139}$

A more definitive genetic component of a specific neuropathic pain syndrome has recently been identified. Primary erythermalgia is a rare, autosomal-dominant condition that manifests by intermittent bouts of swelling of the feet or hands, intense burning pain, and erythe- mia. ${ }^{45}$ Its onset is generally in early childhood, and it may progress until adulthood. ${ }^{45}$ The syndrome may be provoked by warmth or exercise, and relief is commonly found by keeping the affected foot or hand in extreme cold, and is refractory to therapeutic interventions. ${ }^{45,140}$ In a recent study, genotyping was performed from venous blood obtained from 47 individuals from 5 families, 28 of which were affected with erythermalgia. ${ }^{140} \mathrm{~A}$ common allele in the $7.94 \mathrm{cM}$ region of chromosome 2q31-32 was found among the affected individuals in these families. ${ }^{140}$ Further studies with three individuals representing three generations within a Chinese family expressing erythermalgia showed a $\mathrm{T}$ to $\mathrm{A}$ transversion mutation in the gene SCN9A, which codes the $\alpha$-subunit of the $\mathrm{Na}_{\mathrm{V}} 1.7$ sodium channel. ${ }^{45}$ This mutation was found only in individuals that developed erythermalgia, and not in the unaffected family members. ${ }^{45}$ Further studies with four families and two sporadic cases found six missense mutations in SCN9A that were not found in samples from unaffected family members. ${ }^{141}$ These mutations of the Nav1.7 sodium channel may promote abnormal activity of small diameter nociceptors, which would be consistent with the identification of erythermalgia as a small-fiber neuropathy. ${ }^{141,142}$ These observations are supported by the clinical report that intravenous lidocaine followed by oral mexilitene produced a longterm benefit to a child with erythermalgia. ${ }^{143}$

\section{CHALLENGES IN TREATMENT STRATEGIES FOR NEUROPATHIC PAINS: TRANSLATION OF DATA FROM ANIMAL MODELS}

One of the major challenges regarding the development of novel therapies is the development of appropriate, predictive animal models. Whereas the models of traumatic nerve injury that are currently employed produce a reliable behavioral manifestation of tactile and/or thermal hyperesthesia, these behaviors are not directly correlated to the clinical situation. Responses to noxious thermal stimuli require a reflex on the part of the animal, and quantification is based on latency to withdrawal, which is an indirect measurement. Responses to innocuous tactile stimuli are likewise troublesome in that the animal must respond to light touch applied to the plantar aspect of the hindpaw. However, it is difficult to tell if the response represents an enhanced, nocifensive-like behavior (i.e., allodynia), or an enhanced sensitivity to touch (hyperesthesia). Although these behaviors are evoked, the majority of pain complaints involve persistent or spontaneous, paroxysmal pains that are not elicited by an outside stimulus. The challenge, therefore, is to design models that allow the testing of unprovoked and preferably, nonreflexive behaviors. ${ }^{144-146}$

Changes in normal activity may be indicative of an ongoing pain state. Thus, measurement of locomotor 
activity or the propensity of an animal to remain in a small area rather than move freely about may be representative of abnormal pain. Other models that may be helpful include operant conditioning types of models. A simple example is the willingness of a rat to explore a novel area when first placed into the new environment. A more involved example is conditioned place preference. The animal is conditioned to a brightly lit compartment as the place where the treatment (i.e., reward being relief from neuropathic pain) is administered. Thus, if the animal remains in that area, in spite of a preference for the darker compartment, this would be indicative of a antineuropathic effect. ${ }^{147,148}$ An example of this type of operant behavior is shown where rats are trained to make facial contact with a heated probe to obtain water ("reward"). ${ }^{146}$ Inflammation results in diminished tolerance to heat, which is demonstrated by shortened periods of water intake, and this behavior is reversed by morphine. ${ }^{146}$

\section{REFERENCES}

1. Merskey H, Bogduk N. Classifications of chronic pain. Descriptions of chronic pain syndromes and definitions of pain terms. Ed 2. Seattle: IASP Press, 1994.

2. Hansson P, Lacerenza M, Marchettini P. Aspects of clinical and experimental neuropathic pain: the clinical perspective. In: Neuropathic pain: pathophysiology and treatment (Hansson P, Fields H, Hill RG, Marchettini P, eds), Vol 21, pp 1-18. Seattle: IASP Press, 2001.

3. Mitchell SW, Morehouse GR, Ken WW. Gunshot wounds and other injuries of nerves. Philadelphia: Lippincott, 1864.

4. Richards RL. The term 'causalgia.' Med Hist 11:97-99, 1967.

5. Richards RL. Causalgia. A centennial review. Arch Neurol 16: 339-350, 1967.

6. Bonica JJ. Causalgia and other reflex sympathetic dystrophies. In: The management of pain (Bonica JJ, Loeser JD, Chapman CR, Fordyce WE, eds), Vol 1, pp 220-243. Philadelphia: Lea \& Fibiger, 1990.

7. Baron R, Binder A. Complex regional pain syndromes. In: The neurological basis of pain (Pappagallo M, ed), pp 359-378. New York: McGraw-Hill, 2005.

8. Boas RA. Complex regional pain syndromes: symptoms, signs and differential diagnosis. In: Progress in pain research and management (Janig W, Stanton-Hicks M, eds), Vol 6, pp 79-92. Seattle: IASP Press, 1996.

9. Birklein F. Complex regional pain syndrome. J Neurol 252:131138,2005

10. Ghai B, Dureja GP. Complex regional pain syndrome: a review. J Postgrad Med 50:300-307, 2004.

11. Bonicalzi V, Canavero S. Comments on Kingery, PAIN, 73 (1997) 123-139. Controlled randomized trials failed to demonstrate that sympathetic blocks (SB) are more effective than placebo for relieving complex regional pain syndromes (CRPS). Pain 79:317-319, 1999.

12. Roberts WJ. A hypothesis on the physiological basis for causalgia and related pains. Pain 24:297-311, 1986.

13. Scadding JW. Complex regional pain syndromes. In: Textbook of pain (Wall PD, Melzack R, eds), Ed 4, pp 835-849. Edinburgh, UK: Churchill Livingstone, 1999.

14. Schwartzman RJ, McLellan TL. Reflex sympathetic dystrophy. A review. Arch Neurol 44:555-561, 1987.

15. Max MB. Clarifying the definition of neuropathic pain. Pain 96:406-407; author reply 407-408, 2002.

16. Hansson PT, Dickenson AH. Pharmacological treatment of peripheral neuropathic pain conditions based on shared commonalities despite multiple etiologies. Pain 113:251-254, 2005.
17. Jensen TS, Sindrup SH, Bach FW. Test the classification of pain: reply to Mitchell Max. Pain 96:407-408, 2002.

18. Merskey H. Clarifying definition of neuropathic pain. Pain 96: 408-409, 2002.

19. Dworkin RH. An overview of neuropathic pain: syndromes, symptoms, signs, and several mechanisms. Clin J Pain 18:343349, 2002.

20. Boulton AJM. Management of diabetic peripheral neuropathy. Clin Diabetes 23:9-15, 2005.

21. Boulton AJ, Gries FA, Jervell JA. Guidelines for the diagnosis and outpatient management of diabetic peripheral neuropathy. Diabetes Med 15:508-514, 1998.

22. Pappagallo M. Peripheral neuropathic pain. In: The neurological basis of pain (Pappagallo M, ed), pp 321-341. New York: McGraw-Hill, 2005.

23. Nurmikko TJ. Postherpetic neuralgia-a model for neuropathic pain? In: Neuropathic pain: pathophysiology and treatment (Hansson P, Fields H, Hill RG, Marchettini P, eds). Vol 21, pp 151-183. Seattle: IASP Press, 2005.

24. Dworkin RH, Portenoy RK. Proposed classification of herpes zoster pain. Lancet 343:1648, 1994.

25. Dworkin RH, Portenoy RK. Pain and its persistence in herpes zoster. Pain 67:241-251, 1996.

26. Haanpaa M, Dastidar P, Weinberg A, et al. CSF and MRI findings in patients with acute herpes zoster. Neurology 51:1405-1411, 1998.

27. Rowbotham MC, Yosipovitch G, Connolly MK, Finlay D, Forde G, Fields HL. Cutaneous innervation density in the allodynic form of postherpetic neuralgia. Neurobiol Dis 3:205-214, 1996.

28. Oaklander AL. The density of remaining nerve endings in human skin with and without postherpetic neuralgia after shingles. Pain 92:139-145, 2001.

29. Oaklander AL, Romans K, Horasek S, Stocks A, Hauer P, Meyer RA. Unilateral postherpetic neuralgia is associated with bilateral sensory neuron damage. Ann Neurol 44:789-795, 1998.

30. Rowbotham MC, Fields HL. The relationship of pain, allodynia and thermal sensation in post-herpetic neuralgia. Brain $119[\mathrm{Pt}$ 2]:347-354, 1996.

31. Watson CP, Morshead C, Van der Kooy D, Deck J, Evans RJ. Post-herpetic neuralgia: post-mortem analysis of a case. Pain 34:129-138, 1988.

32. Watson CP, Deck JH, Morshead C, Van der Kooy D, Evans RJ. Post-herpetic neuralgia: further post-mortem studies of cases with and without pain. Pain 44:105-117, 1991.

33. Nicholson BD. Diagnosis and management of neuropathic pain: a balanced approach to treatment. J Am Acad Nurse Pract 15:3-9, 2003.

34. Scadding JW. Peripheral neuropathies. In: Textbook of pain (Wall PD, Melzack R, eds), Ed 4, pp 815-834. Edinburgh, UK: Churchill Livingstone, 1999.

35. Ossipov MH, Porreca F. Descending modulation of pain. In: The paths of pain (Merskey H, Loeser JD, Dubner R, eds). Seattle: IASP Press, 2005.

36. Ossipov MH, Porreca F. Endogenous pain modulation: Descending excitatory systems. In: Handbook of clinical neurology (Cervero F, Jensen TS, eds). New York: Elsevier, 2005.

37. Porreca F, Ossipov MH, Gebhart GF. Chronic pain and medullary descending facilitation. Trends Neurosci 25:319-325, 2002.

38. Suzuki R, Rygh LJ, Dickenson AH. Bad news from the brain: descending 5-HT pathways that control spinal pain processing. Trends Pharmacol Sci 25:613-617, 2004.

39. Suzuki R, Dickenson AH. Neuropathic pain: nerves bursting with excitement. Neuroreport 11:R17-R21, 2000.

40. Novakovic SD, Eglen RM, Hunter JC. Regulation of Na+ channel distribution in the nervous system. Trends Neurosci 24:473478, 2001.

41. Lai J, Hunter JC, Porreca F. The role of voltage-gated sodium channels in neuropathic pain. Curr Opin Neurobiol 13:291-297, 2003.

42. Sindrup SH, Jensen TS. Efficacy of pharmacological treatments of neuropathic pain: an update and effect related to mechanism of drug action. Pain 83:389-400, 1999. 
43. Rowbotham MC, Davies PS, Fields HL. Topical lidocaine gel relieves postherpetic neuralgia. Ann Neurol 37:246-253, 1995.

44. Rowbotham MC, Davies PS, Verkempinck C, Galer BS. Lidocaine patch: double-blind controlled study of a new treatment method for post-herpetic neuralgia. Pain 65:39-44, 1996.

45. Yang Y, Wang Y, Li S, et al. Mutations in SCN9A, encoding a sodium channel $\alpha$ subunit, in patients with primary erythermalgia. J Med Genet 41:171-174, 2004

46. Wall PD, Gutnick M. Ongoing activity in peripheral nerves: the physiology and pharmacology of impulses originating from a neuroma. Exp Neurol 43:580-593, 1974.

47. Devor M. Neuropathic pain and injured nerve: peripheral mechanisms. Br Med Bull 47:619-630, 1991.

48. Nystrom B, Hagbarth KE. Microelectrode recordings from transected nerves in amputees with phantom limb pain. Neurosci Lett 27:211-216, 1981.

49. Nordin M, Nystrom B, Wallin U, Hagbarth KE. Ectopic sensory discharges and paresthesiae in patients with disorders of peripheral nerves, dorsal roots and dorsal columns. Pain 20:231-245, 1984.

50. Devor M, Seltzer Z. Pathophysiology of damaged nerves in relation to chronic pain. In: Textbook of pain (Wall PD, Melzack R, eds), pp 129-164. London: Churchill Livingstone, 1999.

51. Wall PD, Gutnick M. Properties of afferent nerve impulses originating from a neuroma. Nature 248:740-743, 1974.

52. Devor M, Wall PD. Type of sensory nerve fibre sprouting to form a neuroma. Nature 262:705-708, 1976.

53. Devor M, Govrin-Lippmann R. Selective regeneration of sensory fibers following nerve crush injury. Exp Neurol 65:243-254, 1979.

54. Devor M. Sensory basis of autotomy in rats [editorial] [see comments]. Pain 45:109-110, 1991.

55. Koltzenburg M, Torebjork HE, Wahren LK. Nociceptor modulated central sensitization causes mechanical hyperalgesia in acute chemogenic and chronic neuropathic pain. Brain $117[\mathrm{Pt}$ 3]:579-591, 1994.

56. Kirk EJ. Impulses in dorsal spinal nerve rootlets in cats and rabbits arising from dorsal root ganglia isolated from the periphery. J Comp Neurol 155:165-175, 1974.

57. Bennett GJ. An animal model of neuropathic pain: a review. Muscle Nerve 16:1040-1048, 1993.

58. Tal M, Eliav E. Abnormal discharge originates at the site of nerve injury in experimental constriction neuropathy $(\mathrm{CCI})$ in the rat. Pain 64:511-518, 1996.

59. Chen Y, Devor M. Ectopic mechanosensitivity in injured sensory axons arises from the site of spontaneous electrogenesis. Eur $J$ Pain 2:165-178, 1998.

60. Fried K, Govrin-Lippmann R, Rosenthal F, Ellisman MH, Devor M. Ultrastructure of afferent axon endings in a neuroma. $\mathrm{J} \mathrm{Neu}$ rocytol 20:682-701, 1991.

61. Devor M, Govrin-Lippmann R, Angelides K. Na+ channel immunolocalization in peripheral mammalian axons and changes following nerve injury and neuroma formation. $J$ Neurosci 13 : 1976-1992, 1993.

62. Devor M, Keller CH, Deerinck TJ, Levinson SR, Ellisman MH. $\mathrm{Na}+$ channel accumulation on axolemma of afferent endings in nerve end neuromas in Apteronotus. Neurosci Lett 102:149-154, 1989.

63. Gu JG, MacDermott AB. Activation of ATP P2X receptors elicits glutamate release from sensory neuron synapses. Nature 389: 749-753, 1997.

64. Goldin AL, Barchi RL, Caldwell JH, et al. Nomenclature of voltage-gated sodium channels. Neuron 28:365-368, 2000.

65. Waxman SG, Cummins TR, Dib-Hajj S, Fjell J, Black JA. Sodium channels, excitability of primary sensory neurons, and the molecular basis of pain. Muscle Nerve 22:1177-1187, 1999.

66. Rush AM, Brau ME, Elliott AA, Elliott JR. Electrophysiological properties of sodium current subtypes in small cells from adult rat dorsal root ganglia. J Physiol (Lond) 511 [Pt 3]:771-789, 1998.

67. Scholz A, Appel N, Vogel W. Two types of TTX-resistant and one TTX-sensitive $\mathrm{Na}+$ channel in rat dorsal root ganglion neurons and their blockade by halothane. Eur J Neurosci 10:25472556, 1998.
68. Akopian AN, Souslova V, England S, et al. The tetrodotoxinresistant sodium channel SNS has a specialized function in pain pathways. Nat Neurosci 2:541-548, 1999.

69. Brock JA, Pianova S, Belmonte C. Differences between nerve terminal impulses of polymodal nociceptors and cold sensory receptors of the guinea-pig cornea. J Physiol (Lond) 533:493501,2001

70. Hains BC, Saab CY, Klein JP, Craner MJ, Waxman SG. Altered sodium channel expression in second-order spinal sensory neurons contributes to pain after peripheral nerve injury. J Neurosci 24:4832-4839, 2004.

71. Wood JN, Boorman JP, Okuse K, Baker MD. Voltage-gated sodium channels and pain pathways. J Neurobiol 61:55-71, 2004.

72. Nassar MA, Stirling LC, Forlani G, et al. Nociceptor-specific gene deletion reveals a major role for Nav1.7 (PN1) in acute and inflammatory pain. Proc Natl Acad Sci USA 101:12706-12711, 2004.

73. Cummins TR, Dib-Hajj SD, Waxman SG. Electrophysiological properties of mutant Nav1.7 sodium channels in a painful inherited neuropathy. J Neurosci 24:8232-8236, 2004.

74. Dib-Hajj SD, Rush AM, Cummins TR, et al. Gain-of-function mutation in Nav1.7 in familial erythromelalgia induces bursting of sensory neurons. Brain 128 [Pt 8]:1847-1854, 2005.

75. Gold MS, Weinreich D, Kim CS, et al. Redistribution of $\mathrm{Na}(\mathrm{V}) 1.8$ in uninjured axons enables neuropathic pain. J Neurosci 23:158-166, 2003

76. Lai J, Gold MS, Kim CS, et al. Inhibition of neuropathic pain by decreased expression of the tetrodotoxin-resistant sodium channel, NaV1.8. Pain 95:143-152, 2002.

77. Porreca F, Lai J, Bian D, et al. A comparison of the potential role of the tetrodotoxin-insensitive sodium channels, PN3/SNS and NaN/SNS2, in rat models of chronic pain. Proc Natl Acad Sci USA 96:7640-7644, 1999.

78. Coward K, Plumpton C, Facer P, et al. Immunolocalization of SNS/PN3 and NaN/SNS2 sodium channels in human pain states. Pain 85:41-50, 2000

79. Bucknill AT, Coward K, Plumpton C, et al. Nerve fibers in lumbar spine structures and injured spinal roots express the sensory neuron-specific sodium channels SNS/PN3 and NaN/SNS2. Spine 27:135-140, 2002.

80. Fang X, Djouhri L, Black JA, Dib-Hajj SD, Waxman SG, Lawson $\mathrm{SN}$. The presence and role of the tetrodotoxin-resistant sodium channel $\mathrm{Na}(\mathrm{v}) 1.9(\mathrm{NaN})$ in nociceptive primary afferent neurons. J Neurosci 22:7425-7433, 2002.

81. Priest BT, Murphy BA, Lindia JA, et al. Contribution of the tetrodotoxin-resistant voltage-gated sodium channel NaV1.9 to sensory transmission and nociceptive behavior. Proc Natl Acad Sci USA 102:9382-9387, 2005.

82. Catterall WA. Structure and regulation of voltage-gated $\mathrm{Ca} 2+$ channels. Апnи Rev Cell Dev Biol 16:521-555, 2000.

83. Nowycky MC, Fox AP, Tsien RW. Three types of neuronal calcium channel with different calcium agonist sensitivity. Nature 316:440-443, 1985.

84. McCleskey EW, Fox AP, Feldman DH, et al. $\omega$-Conotoxin: direct and persistent blockade of specific types of calcium channels in neurons but not muscle. Proc Natl Acad Sci USA 84:4327-331, 1987.

85. Kerr LM, Filloux F, Olivera BM, Jackson H, Wamsley JK. Autoradiographic localization of calcium channels with [125I] $\omega$ conotoxin in rat brain. EurJ harmacol 146:181-183, 1988.

86. Holz GG, IV, Dunlap K, Kream RM. Characterization of the electrically evoked release of substance P from dorsal root ganglion neurons: methods and dihydropyridine sensitivity. $J$ Neurosci 8:463-471, 1988.

87. Matthews EA, Dickenson AH. Effects of spinally delivered Nand P-type voltage-dependent calcium channel antagonists on dorsal horn neuronal responses in a rat model of neuropathy. Pain 92:235-246, 2001.

88. Hu LY, Ryder TR, Rafferty MF, et al. Synthesis of a series of 4-benzyloxyaniline analogues as neuronal N-type calcium channel blockers with improved anticonvulsant and analgesic properties. J Med Chem 42:4239-4249, 1999.

89. Scott DA, Wright CE, Angus JA. Actions of intrathecal $\omega$-cono- 
toxins CVID, GVIA, MVIIA, and morphine in acute and neuropathic pain in the rat. Eur J Pharmacol 451:279-286, 2002.

90. Miljanich GP. Ziconotide: neuronal calcium channel blocker for treating severe chronic pain. Curr Med Chem 11:3029-3040, 2004.

91. Atanassoff PG, Hartmannsgruber MW, Thrasher J, et al. Ziconotide, a new N-type calcium channel blocker, administered intrathecally for acute postoperative pain. Reg Anesth Pain Med 25:274-278, 2000.

92. Brose WG, Gutlove DP, Luther RR, Bowersox SS, McGuire D. Use of intrathecal SNX-111, a novel, N-type, voltage-sensitive, calcium channel blocker, in the management of intractable brachial plexus avulsion pain. Clin J Pain 13:256-259, 1997.

93. Staats PS, Yearwood T, Charapata SG, et al. Intrathecal ziconotide in the treatment of refractory pain in patients with cancer or AIDS: a randomized controlled trial. JAMA 291:63-70, 2004.

94. Snutch TP, Sutton KG, Zamponi GW. Voltage-dependent calcium channels- beyond dihydropyridine antagonists. Curr Opin Pharmacol 1:11-16, 2001.

95. Ikeda H, Heinke B, Ruscheweyh R, Sandkuhler J. Synaptic plasticity in spinal lamina I projection neurons that mediate hyperalgesia. Science 299:1237-1240, 2003.

96. Dogrul A, Gardell LR, Ossipov MH, Tulunay FC, Lai J, Porreca F. Reversal of experimental neuropathic pain by T-type calcium channel blockers. Pain 105:159-168, 2003.

97. Matthews EA, Dickenson AH. Effects of ethosuximide, a T-type $\mathrm{Ca}(2+)$ channel blocker, on dorsal horn neuronal responses in rats. Eur J Pharmacol 415:141-149, 2001.

98. Bourinet E, Alloui A, Monteil A, et al. Silencing of the Cav3.2 T-type calcium channel gene in sensory neurons demonstrates its major role in nociception. EMBO J 24:315-324, 2005.

99. Backonja MM, Galer BS. Pain assessment and evaluation of patients who have neuropathic pain. Neurol Clin 16:775-790, 1998.

100. Jensen TS, Gottrup H, Sindrup SH, Bach FW. The clinical picture of neuropathic pain. Eur J Pharmacol 429:1-11, 2001.

101. Arner S, Meyerson BA. Lack of analgesic effect of opioids on neuropathic and idiopathic forms of pain. Pain 33:11-23, 1988.

102. Arner S, Rawal N, Gustafsson LL. Clinical experience of longterm treatment with epidural and intrathecal opioids-a nationwide survey. Acta Anaesthesiol Scand 32:253-259, 1988.

103. Kupers RC, Konings H, Adriaensen H, Gybels JM. Morphine differentially affects the sensory and affective pain ratings in neurogenic and idiopathic forms of pain. Pain 47:5-12, 1991.

104. Kingery WS. A critical review of controlled clinical trials for peripheral neuropathic pain and complex regional pain syndromes. Pain 73:123-139, 1997.

105. Rowbotham MC, Twilling L, Davies PS, Reisner L, Taylor K, Mohr D. Oral opioid therapy for chronic peripheral and central neuropathic pain. N Engl J Med 348:1223-1232, 2003.

106. Gordon DB, Love G. Pharmacologic management of neuropathic pain. Pain Manag Nurs 5:19-33, 2004.

107. Raja SN, Haythornthwaite JA, Pappagallo M, et al. Opioids versus antidepressants in postherpetic neuralgia: a randomized, placebo-controlled trial. Neurology 59:1015-1021, 2002.

108. Watson CPN, Babul N. Efficacy of oxycodone in neuropathic pain: A randomized trial in postherpetic neuralgia. Neurology 50:1837-1841, 1998.

109. Watson CPN, Moulin D, Watt-Watson J, Gordon A, Eisenhoffer J. Controlled-release oxycodone relieves neuropathic pain: a randomized controlled trial in painful diabetic neuropathy. Pain 105: 71-78, 2003.

110. Hansson P. Neuropathic pain: clinical characteristics and diagnostic workup. Eur J Pain 6 [Suppl A]:47-50, 2002.

111. Backonja M, Beydoun A, Edwards KR, et al. Gabapentin for the symptomatic treatment of painful neuropathy in patients with diabetes mellitus: a randomized controlled trial. JAMA 280:18311836, 1998.

112. Rowbotham MC, Reisner-Keller LA, Fields HL. Both intravenous lidocaine and morphine reduce the pain of postherpetic neuralgia. Neurology 41:1024-1028, 1991.

113. Backonja M. Anticonvulsants and antiarrhythmics in the treatment of neuropathic pain syndromes. In: Neuropathic pain: patho- physiology and treatment (Hansson P, Fields H, Hill RG, Marchettini P, eds). Vol 21, pp 185-201. Seattle: IASP Press, 2001.

114. Robbins WR, Staats PS, Levine J, et al. Treatment of intractable pain with topical large-dose capsaicin: preliminary report. Anesth Analg 86:579-583, 1998.

115. Forouzanfar T, Koke AJ, van Kleef M, Weber WE. Treatment of complex regional pain syndrome type I. Eur J Pain 6:105-122, 2002.

116. Perez RS, Kwakkel G, Zuurmond WW, de Lange JJ. Treatment of reflex sympathetic dystrophy (CRPS type 1): a research synthesis of 21 randomized clinical trials. J Pain Symptom Manage 21: 511-526, 2001.

117. Sunderland S. Nerves and nerve injuries. London: Churchill Livingstone, 1993.

118. Bohm E. Das Sudecksche Syndrom. [Complex regional pain syndrome, type I.] Hefte Unfallheilkunde 174:241-250, 1985.

119. Jensen TS, Nikolajsen L. Phantom pain and other phenomena after amputation. In: Textbook of pain (Wall PD, Melzack R, eds), Ed 4, pp 799-814. Edinburgh, UK: Churchill Livingstone, 1999.

120. Abramson AS, Feibel A. The phantom phenomenon: its use and disuse. Bull N Y Acad Med 57:99-112, 1981.

121. Vickers ER, Cousins MJ. Neuropathic orofacial pain part 1-prevalence and pathophysiology. Aust Endod J 26:19-26, 2000.

122. Stankus SJ, Dlugopolski M, Packer D. Management of herpes zoster (shingles) and postherpetic neuralgia. Am Fam Physician 61:2437-2444, 2447-2438, 2000.

123. Hope-Simpson RE. Postherpetic neuralgia. J R Coll Gen Pract 25:571-575, 1975.

124. Choo PW, Galil K, Donahue JG, Walker AM, Spiegelman D, Platt R. Risk factors for postherpetic neuralgia. Arch Intern Med 157:1217-1224, 1997.

125. Bowsher D. The lifetime occurrence of herpes zoster and prevalence of post-herpetic neuralgia: a retrospective survey in an elderly population. Eur J Pain 3:335-342, 1999.

126. Melton LJ, Dyck PJ. Epidemiology. In: Diabetic neuropathy (Dyck PJ, ed), pp 27-35. Philadelphia: WB Saunders Co., 1987.

127. Ziegler D, Gries FA, Spuler M, Lessmann F. The epidemiology of diabetic neuropathy. Diabetic Cardiovascular Autonomic Neuropathy Multicenter Study Group. J Diabetes Complications 6:49-57, 1992.

128. Ratzmann KP, Raschke M, Gander I, Schimke E. Prevalence of peripheral and autonomic neuropathy in newly diagnosed type II (noninsulin-dependent) diabetes. $J$ Diabeest Complications 5:1-5, 1991

129. Haanpaa ML, Laippala PA, Nurmikko TJ. Thermal and tactile perception thresholds in acute herpes zoster. Eur J Pain 3:375386, 1999.

130. Veldman PHJM, Goris RJA. Multiple reflex sympathetic dystrophy. Which patients are at risk for developing a recurrence of reflex sympathetic dystrophy in the same or another limb. Pain 64:463-466, 1996.

131. Veldman PHJM, Reynen HM, Arntz IE, Goris RJA. Signs and symptoms of reflex sympathetic dystrophy: prospective study of 829 patients. The Lancet 342:1012-1016, 1993.

132. Allen G, Galer BS, Schwartz L. Epidemiology of complex regional pain syndrome: a retrospective chart review of $134 \mathrm{pa}-$ tients. Pain 80:539-544, 1999.

133. Schwartzman RJ, Kerrigan J. The movement disorder of reflex sympathetic dystrophy. Neurology 40:57-61, 1990.

134. Ochoa JL, Verdugo RJ, Campero M. Pathophysiological spectrum of organic and psychogenic disorders in neuropathic pain patients fitting the description of causalgia or reflex sympathetic dystrophy. In: Progress in pain research and management: Proceedings of the 7th World Congress on Pain (Gebhart GF, Hammond DL, Jensen TS, eds). Vol 2, pp 483-494. Seattle: IASP Press, 1994.

135. Mailis A, Wade J. Profile of Caucasian women with possible genetic predisposition to reflex sympathetic dystrophy: a pilot study. Clin J Pain 10:210-217, 1994. 
136. Kemler MA, van de Vusse AC, van den Berg-Loonen EM, Barendse GA, van Kleef M, Weber WE. HLA-DQ1 associated with reflex sympathetic dystrophy. Neurology 53:1350-1351, 1999.

137. van Hilten JJ, van de Beek WJ, Roep BO. Multifocal or generalized tonic dystonia of complex regional pain syndrome: a distinct clinical entity associated with HLA-DR13. Ann Neurol 48: 113-116, 2000.

138. van de Beek WJ, van Hilten JJ, Roep BO. HLA-DQ1 associated with reflex sympathetic dystrophy. Neurology 55:457-458, 2000.

139. van de Beek W-JT, Roep BO, van der Slik AR, Giphart MJ, van Hilten BJ. Susceptibility loci for complex regional pain syndrome. Pain 103:93-97, 2003.

140. Drenth JP, Finley WH, Breedveld GJ, et al. The primary erythermalgia-susceptibility gene is located on chromosome 2q31-32. Am J Hum Genet 68:1277-1282.

141. Drenth JP, Te Morsche RH, Guillet G, Taieb A, Kirby RL, Jansen JB. SCN9A Mutations define primary erythermalgia as a neuropathic disorder of voltage gated sodium channels. J Invest Dermatol 124:1333-1338, 2005.

142. Davis MDP, Sandroni P, Rooke TW, Low PA. Erythromelalgia: vasculopathy, neuropathy, or both?: a prospective study of vas- cular and neurophysiologic studies in erythromelalgia. Arch Dermatol 139:1337-1343, 2003.

143. Nathan A, Rose JB, Guite JW, Hehir D, Milovcich K. Primary erythromelalgia in a child responding to intravenous lidocaine and oral mexiletine treatment. Pediatrics 115:e504-e507, 2005.

144. Mauderli AP, Acosta-Rua A, Vierck CJ. An operant assay of thermal pain in conscious, unrestrained rats. J Neurosci Methods 97:19-29, 2000.

145. Vierck CJ Jr, Kline RT, Wiley RG. Comparison of operant escape and innate reflex responses to nociceptive skin temperatures produced by heat and cold stimulation of rats. Behav Neurosci 118 : 627-635, 2004.

146. Neubert JK, Widmer CG, Malphurs W, Rossi HL, Vierck CJ Jr, Caudle RM. Use of a novel thermal operant behavioral assay for characterization of orofacial pain sensitivity. Pain 116:386-395, 2005.

147. Huang EY, Chen CM, Tao PL. Supraspinal anti-allodynic and rewarding effects of endomorphins in rats. Peptides 25:577-583, 2004.

148. Oe K, Narita M, Imai S, et al. Inhibition of the morphine-induced rewarding effect by direct activation of spinal protein kinase $\mathrm{C}$ in mice. Psychopharmacology (Berl) 177:55-60, 2004. 